\title{
Modeling and Static Structural Analysis of Finite Element for a Truck Crane's Frame
}

\author{
Guo-Bin LI ${ }^{\mathrm{a}}$, Nan XU ${ }^{\mathrm{b}}$, Rui-Jun ZHANG ${ }^{\mathrm{c}}$ \\ School of Mechanical and Electronic Engineering, Shandong Jianzhu University, Jinan 25010, China \\ aliguobin486@126.com, ${ }^{\text {bxunan06@sdjzu.edu.cn, }{ }^{c} z h a n g r u i j u n @ s d j z u . e d u . c n ~}$
}

Keywords: Truck Crane, Frame, Finite Element Method, ANSYS Workbench.

\begin{abstract}
A type of truck crane frame was studied and the three-dimensional model is built by CATIA, then the model is imported into ANSYS Workbench to analyze the frame. By analyzing, the results of stress and deformation are got in 2 typical conditions; meanwhile weak parts of structure are pointed out, like fixed outrigger and main frame connection and fixed outrigger and unfixed outrigger connection. The analysis has important reference value for the improvement and optimization design of the frame.
\end{abstract}

\section{Introduction}

Frame, welded by steel plates, is thin-walled box structure with single or multi-room. And frame, one of main structure of truck crane, is crucial to the overall performance. Its structural malfunctions can result in serious consequences. Structural deformation and breakdown of frame can be caused by low strength. In addition, insufficient stiffness can lead to instability on working conditions that does damage to crane turntable, even getting crane capsized.

Owing to complicated structures and load force, it is very difficult to calculate and analyze frame accurately. Finite element method has been a major means to design structure of frame [1].

3D model of a truck crane's frame is established by CATIA and ANSYS Workbench is used to analyze the stress and deformation of the frame. According to results, structural weak points are found. The analysis also has important reference value in providing an improvement and optimization to structure of the frame.

\section{The Model of the Truck crane's Frame}

\section{The Structure of the Frame}

The frame is principally made up of main frame, fixed outriggers and unfixed outriggers. The main frame is a large concave enclosed box-type structure within transverse bulkheads to strengthen the overall torsional performance. There are also longitudinal and transverse support plates in the crane turntable to ensure sufficient stiffness. H-legs are put to use in the truck crane. The fixed outriggers and main frame are welded together. The unfixed outriggers are pushed by horizontal hydro-cylinder and supported on ground by means of vertical legs. And they can synchronously stretch out and draw back in the fixed outriggers.

When establishing the 3D model of frame by CATIA, it is necessary to get the structure of the frame simplified properly in order to meet the requirements of project and research. Omit some installation parts with small loads and little influence on structural deformation. Neglect some minor assembled holes and leave out some fillet surfaces, bosses, strengthening ribs and board edges used to ensure welding quality.

\section{The Finite Element Model of the Frame}

The CATIA geometric model is imported into ANSYS Workbench to build the finite element model. Meshing is a key step in the FEA of the frame. Controlling element size and meshing methods are effective ways to ensure meshing quality of the frame [2]. Hexahedron elements should be dominant and a small amount of tetrahedron elements can be applied to transition. As for regular 
structure, sweep meshing method is usually considered as the priority. To other structure, automatic method is generally utilized [3]. The regions of key stressed members and stress concentration ares should be meshed densely, such as the cover plate and turntable connections, the fixed outriggers and main frame connections and the fixed outriggers and unfixed outriggers connections. Some parts with small loads like bulkheads can be meshed sparsely.

The frame material is HG60, the physical properties are: modulus E=205 GPa, Poisson ratio $\mu=0.3$, and density $\rho=7850 \mathrm{~kg} / \mathrm{m} 3$. Its mechanical properties are: minimum yield strength $460 \mathrm{MPa}$, minimum tensile strength $570 \mathrm{MPa}$, max tensile strength $730 \mathrm{MPa}$, the material allowance stress is $317 \mathrm{MPa}$.

The finite analysis model is shown in Fig.1 with 3980335 nodes and 628442 elements.

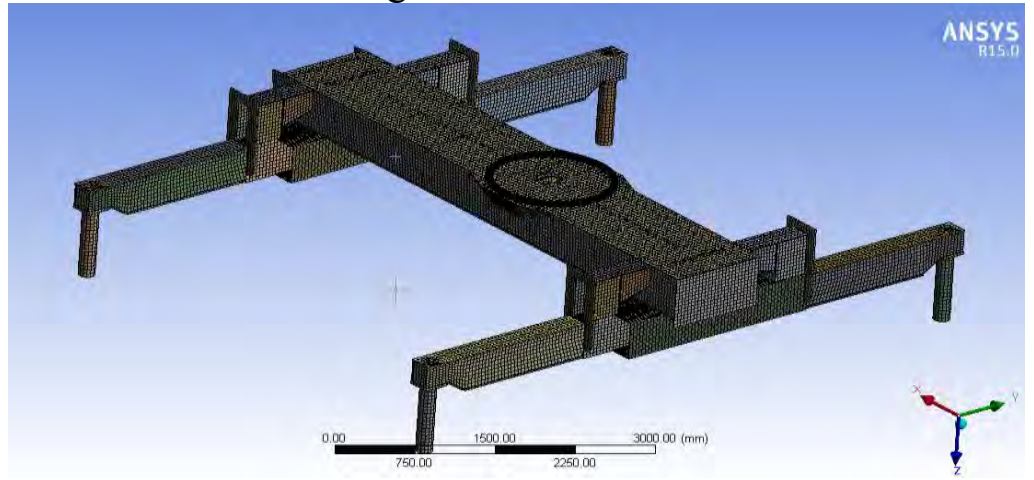

Fig. 1 Finite Element Model of Frame

\section{The Loads of the Frame}

The truck crane's frame is loaded by its own gravity G1, superstructure's gravity G2, crane load GQ and moment M generated by G2 and GQ. G1 is automatically obtained by setting material's destiny in ANSYS Workbench. The superstructure's gravity G2 is $19.8 \mathrm{t}$. When GQ $=21 \mathrm{t}$ and the crane radius $\mathrm{L}=5 \mathrm{~m}$, the truck crane chassis is loaded largest static forces and it is in the most dangerous state. So the vertical force GP loaded on the frame is $400.13 \mathrm{KN}$ and overall moment is $1029 \mathrm{KN} \cdot \mathrm{m}$.

\section{The Typical Working Conditions and Boundary Conditions}

In order to ensure the accuracy of finite analysis model, it is essential to select precise working and boundary conditions [4].

There are 2 typical working conditions. Condition 1: when boom turns right for 90 degrees, the frame has the maximum roll moment that can easily result in a rollover. Condition 2: there is maximum reaction force in the right rear unfixed outrigger when crane boom is right above the outrigger.

The loads and boundary conditions of 2 typical working conditions are shown in Fig.2 and Fig.3. $(+\mathrm{X}$ : front; + Y: right; $+\mathrm{Z}$ : down)

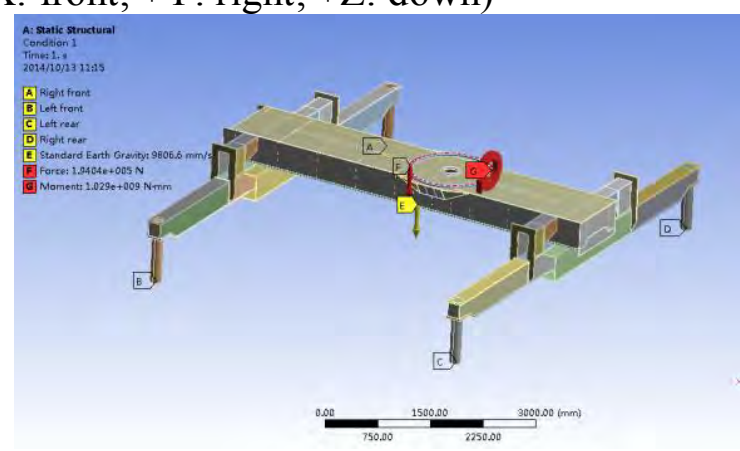

Fig. 2 Loads and Boundary Conditions of Condition 1

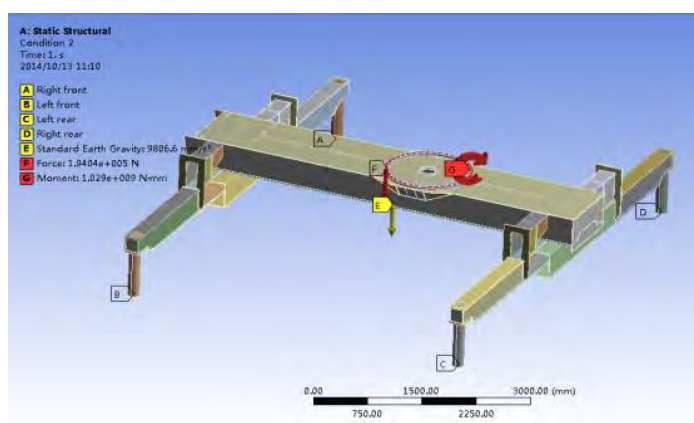

Fig. 3 Loads and Boundary Conditions of Condition 


\section{The Finite Element Analysis of the Frame}

\section{The Static Structural Results of the frame's Analysis}

Condition 1: as is shown in Fig.4, there are 3 relatively large stress. Firstly, the maximum Von-Mises stress occurs in inclined support and cover plate connection at the right side of turntable center, it is about $677.60 \mathrm{MPa}$. Secondly, the stress is about $412.04 \mathrm{MPa}$, at the right rear fixed outrigger and main frame connection. Thirdly, the stress is $297.80 \mathrm{MPa}$, at the right rear outrigger and fixed outrigger connection. As is shown in Fig.5, the maximum total deformation is about $14.70 \mathrm{~mm}$, at the right side of cover plate which is near turntable center.

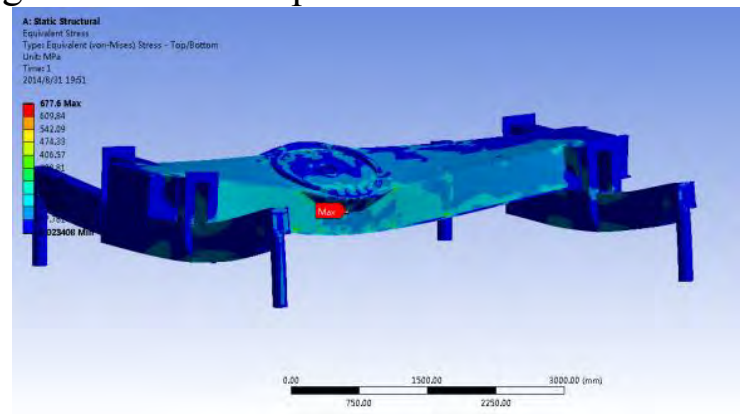

Fig. 4 Equivalent Stress Contours for Condition 1

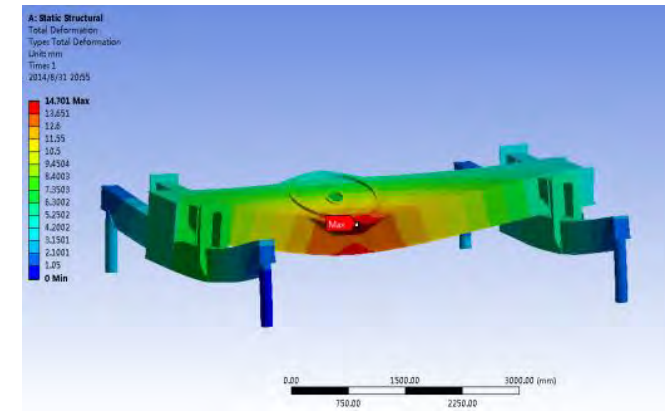

Fig.5 Equivalent Deformation Contours for Condition 1

Condition 2: as is shown in Fig.6, in this case, there are 3 relatively large stresses. Firstly, the maximum Von-Mises stress occurs in inclined support and cover plate connection at the right rear of turntable center, it is about $525.57 \mathrm{MPa}$. Secondly, the stress is about $481.94 \mathrm{MPa}$, at the right rear fixed outrigger and main frame connection. Thirdly, the stress is $377.04 \mathrm{MPa}$, at the right rear outrigger and fixed outrigger connection. As is shown in Fig.7, the maximum total deformation is about $13.07 \mathrm{~mm}$, at the right rear of cover plate which is near turntable center.

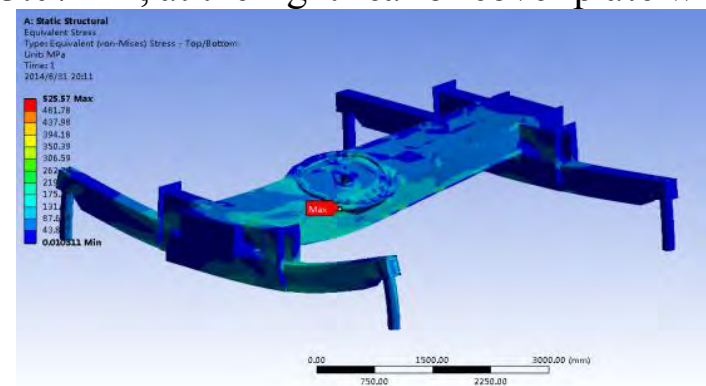

Fig.6 Equivalent Stress Contours for Condition 2

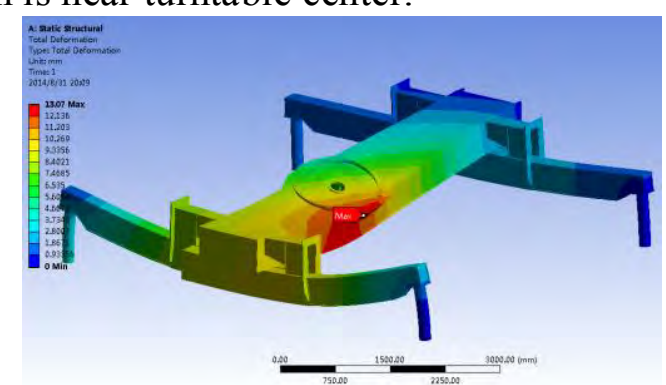

Fig.7 Equivalent Deformation Contours for Condition 2

\section{Results Analysis}

As the inclined support and cover plate connections at the right side of turntable center are loaded by superstructure's gravity and crane load and the contact area is very small, the maximum Von-Mises stresses of 2 conditions all occur there. However, there is little influence on the entire structure of frame. In addition, there is relatively large stress at fixed outrigger and main frame connection in the 2 cases, for the reason that these parts are angles not round corners for transition. Large stress also occurs at fixed outrigger and unfixed outrigger connection at the right side of chassis. Even if not beyond allowable stress, internal cracks of structure should be prevented absolutely.

In the 2 conditions, not only does the maximum total deformation occur at the right side of frame, but the frame's deformation at the right side is obviously larger than that at the left side. The 
maximum total deformation is within the design requirements of crane, demonstrating the overall stiffness of frame also meets requirements.

\section{Summary}

(1)At the right side of frame, there is large stress at fixed outrigger and main frame connection and fixed outrigger and unfixed outrigger connection. So it is necessary to get the dangerous areas improved and strengthened and pay attention to the welding quality.

(2) The larger stress mainly occur in 2 typical working conditions: the crane's beam is right above right front unfixed outrigger; it turns right for 90 degrees; it is right above the right rear unfixed outrigger. The 2 conditions are usually taken into consideration when analyzing.

(3) Selecting properly simplified model and precise working and boundary conditions is vital to ensure the accuracy of the finite element analysis of frame, providing the improvement and optimization of similar truck cranes' frame structure with theoretical basis.

\section{References}

[1]Zhu Maotao, Chen Long, Li Zhibing. Means of support and dynamic characteristics of the farm vehicles chassis, J. Transactions of Chinese Society of Agricultural Engineering, 34(2003) 142-144.

[2]Mi Chengji, Gu Zhengqi, Yang Qingquan. Frame fatigue life assessment of a mining dump truck based on finite element method and multibody dynamic analysis, J. Engineering Failure Analysis, 23(2012) 18-26.

[3]Chen Yanhong, Zhu Feng. The finite element analysis and the optimization design of the Yj3128-type dump truck's sub-frames based on ANSYS, J. Procedia Earth and Planetary Science. 2(2011) 133-138.

[4]Zhang Nana, Zhao Yun, Liu Hong xin. Light design of frame for self-propelled chassis rice transport, J. Transaction of the CSAE. 28(2012) 55-59. 